\title{
SISTEM INFORMASI MANAJEMEN RAWAT JALAN DI KLINIK PRATAMA: SURAT KETERANGAN MEDIS, LAPORAN KUNJUNGAN PASIEN, OBAT, PEMBAYARAN
}

\author{
Hendra Rohman ${ }^{1 *}$, Melisa Wulandari ${ }^{2}$ \\ ${ }^{12}$ Prodi Rekam Medis dan Informasi Kesehatan, Politeknik Kesehatan Bhakti Setya Indonesia \\ Jl. Janti Gedongkuning No.336, Banguntapan, Bantul, Yogyakarta \\ *Email: hendrarohman@mail.ugm.ac.id
}

\begin{abstract}
Abstrak
Sistem yang digunakan oleh petugas pendaftaran pasien rawat jalan di Klinik Pratama Mitra Sehat menggunakan microsoft excel sejak tahun 2014. Dalam penerapannya, sistem microsoft excel hanya digunakan untuk input identitas sosial. Selain itu tidak memiliki keamanan sistem, kontrol sulit dilakukan, pengolahan data dan pembuatan laporan dilakukan secara manual serta informasi yang dihasilkan tidak lengkap sehingga terjadi kesulitan bagi petugas untuk memberikan pelayanan yang efektif dan efisien kepada pasien. Tujuannya untuk merancang sistem informasi manajemen pasien rawat jalan berbasis web menggunakan metode system development life cycle (SDLC). Hasil dari sistem ini terdapat menu pendaftaran, pelayanan, pembayaran, manajemen data dan laporan yang dapat membantu petugas dalam memberikan pelayanan pendaftaran pasien baru, pendaftaran pasien lama, penyimpanan hasil pemeriksaan, penyimpanan pembayaran, khususnya dalam pembuatan surat keterangan medis dan pembuatan laporan kunjungan pasien, obat dan pembayaran
\end{abstract}

Kata kunci: Rekam medis elektronik, pendaftaran pasien.

\section{PENDAHULUAN}

Menurut Profil Kesehatan Provinsi DI Yogyakarta tahun 2017 Dinas Kesehatan Daerah Istimewa Yogyakarta merupakan institusi yang ditunjuk untuk menyelenggarakan urusan Pemerintah DIY di bidang kesehatan yang memiliki tugas pokok dan fungsi sebagai penggerak pembangunan di bidang kesehatan dalam rangka meningkatkan derajat kesehatan masyarakat DIY. Agar proses pembangunan kesehatan berjalan sesuai dengan arah dan tujuan, diperlukan manajemen yang baik sebagai langkah dasar pengambilan keputusan dan kebijakan di semua tingkat administrasi pelayanan kesehatan. Pencatatan dan pelaporan kegiatan pelayanan kesehatan perlu dikelola dengan baik dalam suatu sistem informasi kesehatan. Sistem informasi kesehatan (SIK) yang evidence based diupayakan untuk dapat menyediakan data dan informasi yang akurat, lengkap dan tepat waktu. Untuk itu, peran data dan informasi kesehatan menjadi sangat penting dan semakin dibutuhkan dalam manajemen kesehatan oleh berbagai pihak.

Klinik Pratama Mitra Sehat merupakan klinik umum yang berlokasi di Jalan Imogiri Timur KM 6 Dladan Ngebleng Tamanan Banguntapan Bantul Yogyakarta. Hal ini bertujuan untuk memberikan kontribusi pelayanan kesehatan medis dasar dan penunjang kesehatan bagi masyarakat sekitar.

Berdasarkan hasil wawancara dengan petugas pendaftaran di Klinik Pratama Mitra Sehat menjelaskan bahwa sistem yang digunakan oleh petugas pendaftaran pasien rawat jalan di Klinik Pratama Mitra Sehat menggunakan microsoft excel sejak tahun 2014. Microsoft excel hanya digunakan untuk input pendaftaran pasien. Sistem tersebut masih sederhana, belum ada hak akses pengguna terkait keamanan datanya, desain antar muka terlihat membosankan, kurang efektif dalam melakukan input data pasien, sulit melakukan kontrol data karena isi dari sistem informasi hanya berupa identitas sosial sehingga terjadi tingkat kesalahan dalam melakukan kontrol sangat besar. Klinik Pratama Mitra Sehat menggunakan sistem penyimpanan data pasien berdasarkan kelompok keluarga (family folder). Sistem penyimpanan data tersebut yaitu pada saat pasien berkunjung pertama kali ke Klinik Pratama Mitra Sehat akan mendapat satu nomor rekam medis untuk satu keluarga. Apabila pasien berobat maka data riwayat penyakit atau berkas rekam medis satu keluarga akan diambil juga dalam kegiatan pemberian pelayanan. Selain itu di Klinik Mitra Sehat terdapat permasalahan yaitu kesulitan dalam proses 
pencarian data pasien, terdapat nomor rekam medis ganda, proses pengolahan data dan pembuatan laporan masih dilakukan secara manual. Sehingga terjadi kesulitan bagi petugas untuk memberikan pelayanan yang efektif dan efisien terhadap pasien sehingga informasi yang dihasilkan tidak lengkap.

Dengan permasalahan yang dihadapi klinik tersebut, dibutuhkan suatu sistem yang mampu mengakses data atau informasi yang tersedia agar dapat dikelola dengan cepat dan akurat dalam upaya peningkatan mutu pelayanan klinik, mempercepat proses pencarian dan input data pasien rawat jalan, up to date dan penggunaan data lebih aman. Sehingga perlu dilakukan perancangan sistem informasi berbasis web.

\section{METODE PENGEMBANGAN SISTEM}

Metode pengembangan sistem penelitian ini adalah system development life cycle (SDLC), sebuah proses pengembangan software yang digunakan oleh analyst system, untuk mengembangkan sebuah sistem informasi yang sesuai dengan kebutuhan dari pengguna. SDLC mencakup kebutuhan (requirement), validasi, pelatihan, kepemilikan (user ownership) sebuah sistem informasi, yang dapat diperoleh melalui investigasi, analisis, desain, uji coba, implementasi, perbaikan sistem dan perawatan software (Hakam, 2016). Teknik pengumpulan data pada tahapan identifikasi kebutuhan, perancangan dan uji coba rancangan dilakukan melalui kolaborasi antara peneliti dengan pengguna sistem. Proses pengumpulan dan pengambilan data dilakukan dengan melakukan wawancara dengan petugas yang berkompeten, serta melakukan observasi secara langsung terhadap pelaksanaan kegiatan pendaftaran.

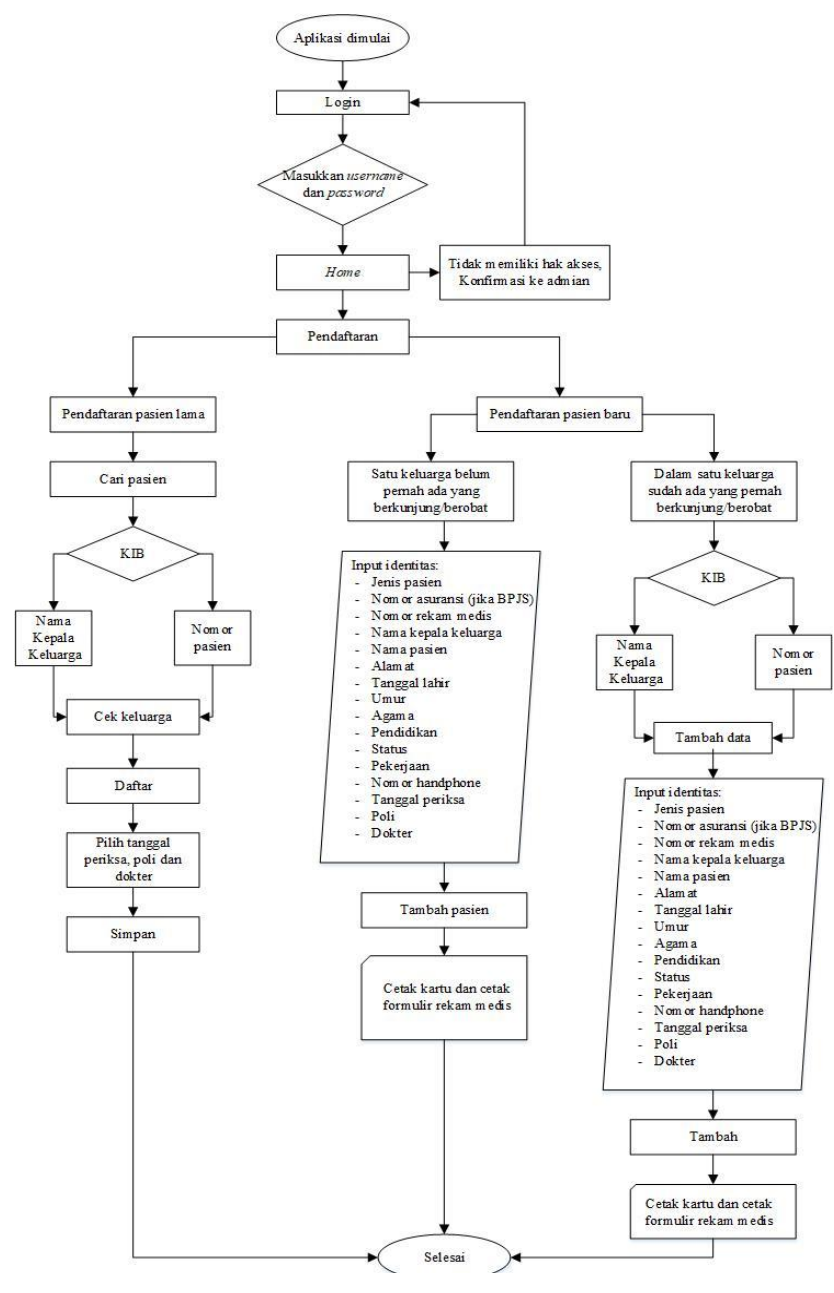

Gambar 1. Flowchart alur pendaftaran

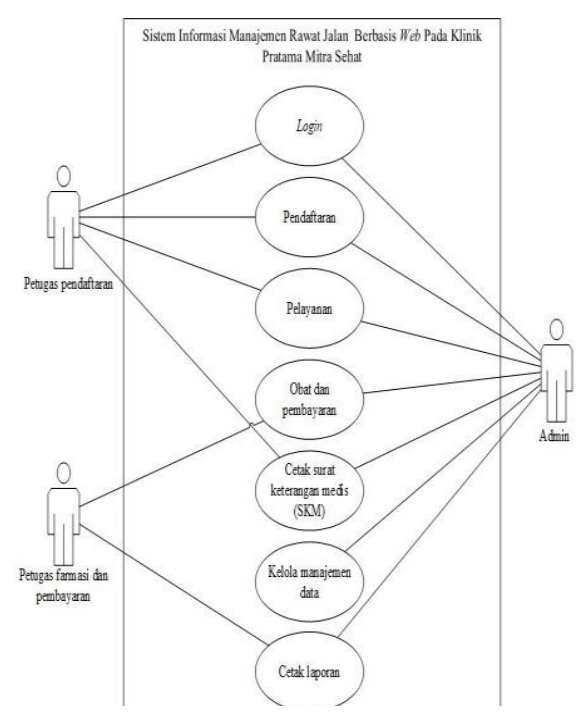

Gambar 2. UML use case 


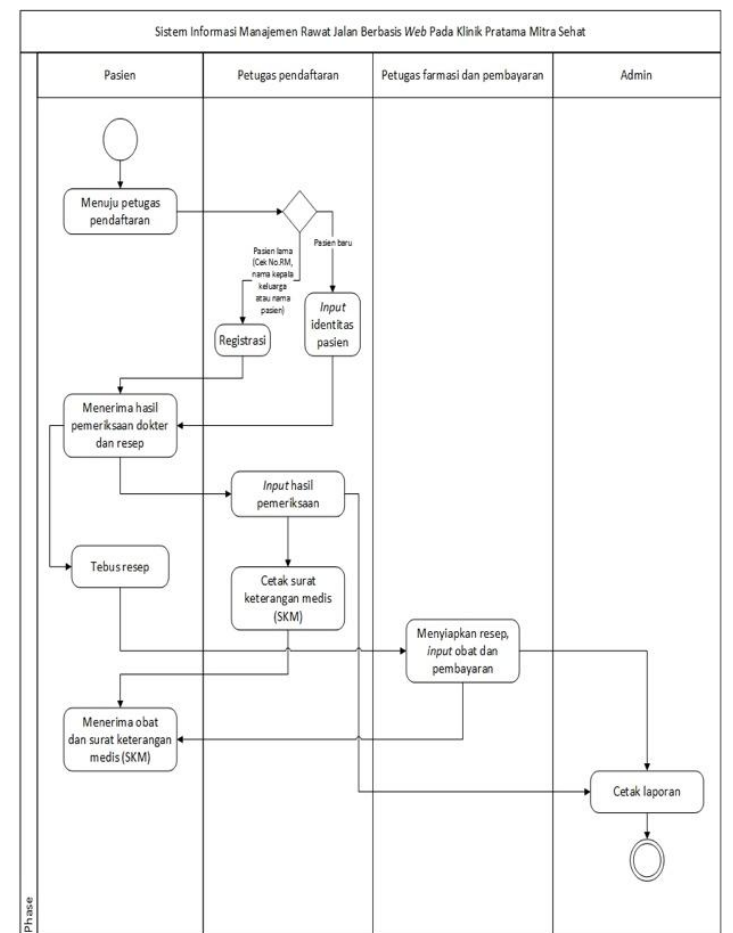

Gambar 3. UML activity

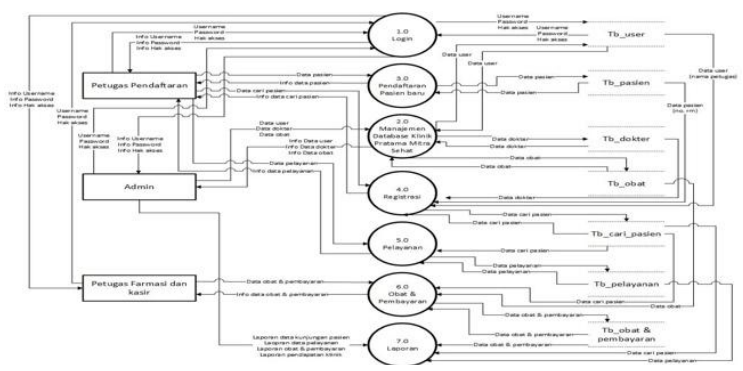

Gambar 4. Data flow diagram (DFD)
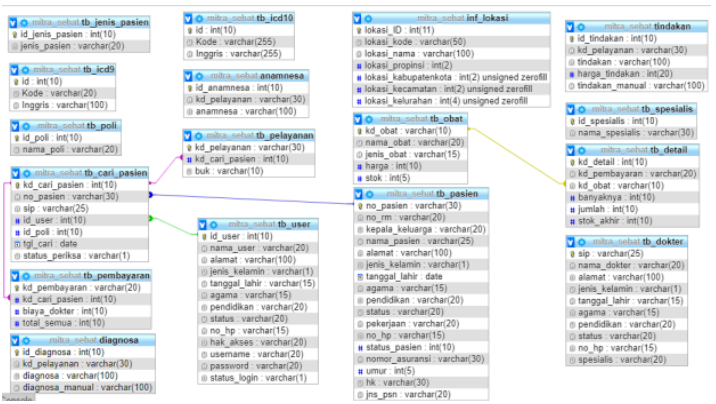

Gambar 5. Relasi antar tabel

\section{HASIL DAN PEMBAHASAN}

Klinik Pratama Mitra Sehat berdiri pada tanggal 15 Februari 2012 di bawah naungan CV Mitra Sehat. Seiring dengan perkembangan kebutuhan akan kesehatan masyarakat
Kabupaten Bantul, maka Klinik Pratama Mitra Sehat sudah sewajarnya ikut berperan dalam pelayanan kesehatan masyarakat dalam menunjang program pemerintah, dengan memberikan pelayanan medis dasar yang terjangkau bagi masyarakat.

Pencatatan identitas pasien pada pendaftaran pasien rawat jalan di Klinik Pratama Mitra Sehat dilakukan secara komputerisasi yaitu menggunakan sisten microsoft excel. Input data pada microsoft excel yaitu saat pertama kali pasien berobat pada Klinik Pratama Mitra Sehat. Input data pada sistem microsoft excel yaitu nomor rekam medis, nama pasien, umur, jenis kelamin, alamat, nomor handphone, nama perusahaan, nomor BPJS dan keterangan untuk informasi tambahan pasien.

Konsep awal unit kerja rekam medis untuk klinik pratama dapat dimulai dari perencanaan secara bertahap mulai identiikasi hingga pemilihan alternatif agar dapat diimplentasikan sesuai standar dan kebutuhan (Meianti, 2018). Identifikasi masalah pada Klinik Pratama Mitra Sehat diantaranya microsoft excel hanya untuk menyimpan identitas sosial pasien saat pertama kali berkunjung, sistem masih sederhana dan belum terdapat keamananya, kurang efektif dalam melakukan input data pasien, sulit melakukan kontrol karena isi dari sistem informasi hanya berupa identitas sosial sehingga tingkat kesalahan dalam melakukan kontrol akan sangat besar, proses pengolahan data dan pembuatan laporan masih dilakukan secara manual.

Kebutuhan input data yang diperlukan oleh sistem informasi pendaftaran rawat jalan di Klinik Pratama Mitra Sehat meliputi data sosial pasien, data pemeriksaan, data pembayaran, data surat keterangan medis, data manajemen data dan data laporan. Software yang diperlukan untuk menjalankan sistem informasi adalah MySQL sebagai database, Xampp versi 3.2.3 sebagai control panel application dan aplikasi browser untuk menjalankan sistem informasi.

Pada sistem ini, terdapat tiga pengguna yang dapat login dan mengoperasikan sistem informasi, yaitu admin, petugas pendaftaran serta petugas obat dan pembayaran. Dimana yang berperan menjadi admin yaitu penanggung jawab pendaftaran yang memiliki akses untuk mengelola sistem informasi diantaranya mengelola registrasi, laporan kunjungan pasien, 
laporan obat dan pembayaran serta memiliki wewenang untuk menambah user, dokter, obat, jenis pasien, jenis pelayanan, data diagnosa, data tindakan dan data spesialis dokter. Petugas pendaftaran memiliki hak akses untuk mengelola pendaftaran, pelayanan (pemeriksaan) pasien, membuat surat keterangan medis baik sehat maupun sakit dan laporan kunjungan pasien. Sedangkan petugas obat dan pembayaran memiliki hak akses untuk data obat dan pembayaran, laporan obat serta laporan pembayaran.

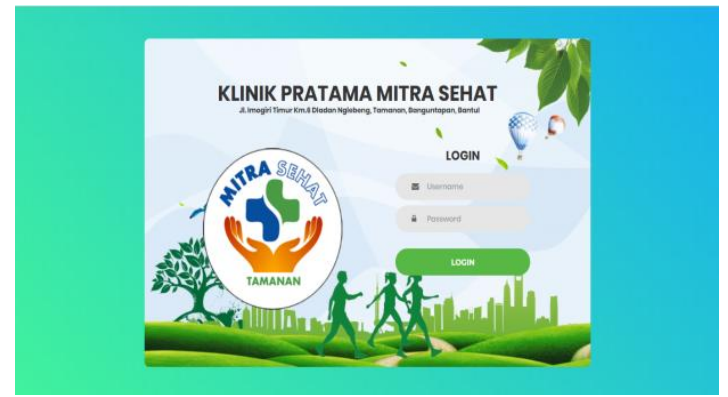

Gambar 6. Tampilan login

Pada halaman utama akan menampilkan pendapatan perhari, pendapatan perbulan, jumlah pasien dan grafik pendapat perbulan.

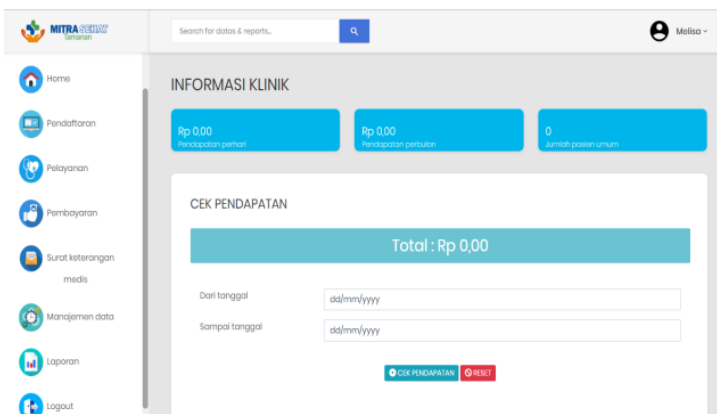

Gambar 7. Menu utama

Pada halaman ini, pendaftaran pasien baru dengan memilih tombol pasien baru kemudian tersedia form untuk mengisi data sosial pasien yang mendaftar sedangkan untuk mendaftar pasien lama dapat dilakukan dengan mencari data pasien di kolom pencarian dengan menggunakan nama ataupun nomor rekam medis. Setelah menemukan data pasien, terdapat tiga pilihan yaitu cek keluarga, tambah data dan cetak kartu. Pilih cek keluarga kemudian pilih nama pasien dalam satu keluarga yang akan berobat lalu pilih daftar untuk mendaftar jenis pelayanan yang diinginkan dan dokter yang memeriksa kemudian pilih simpan.

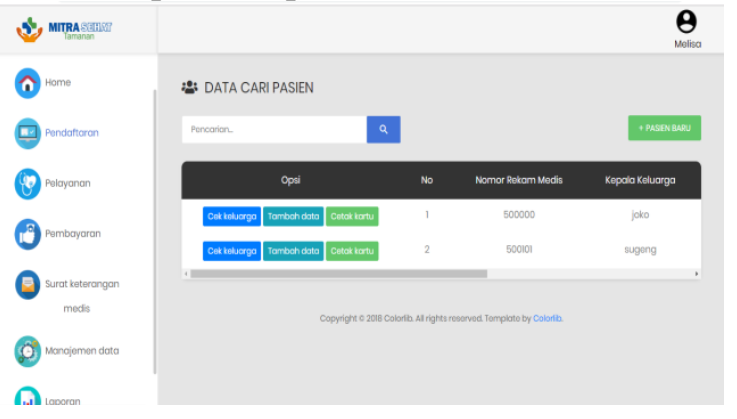

Gambar 8. Menu pendaftaran

Pada menu pendaftaran tersebut sistem informasi dapat mencetak kartu berobat dan mencetak formulir rekam medis.

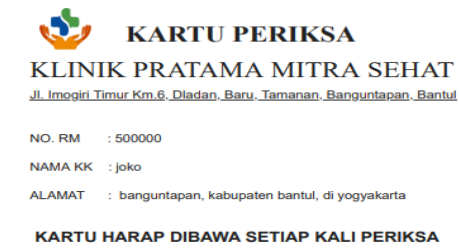

Gambar 9. Kartu berobat

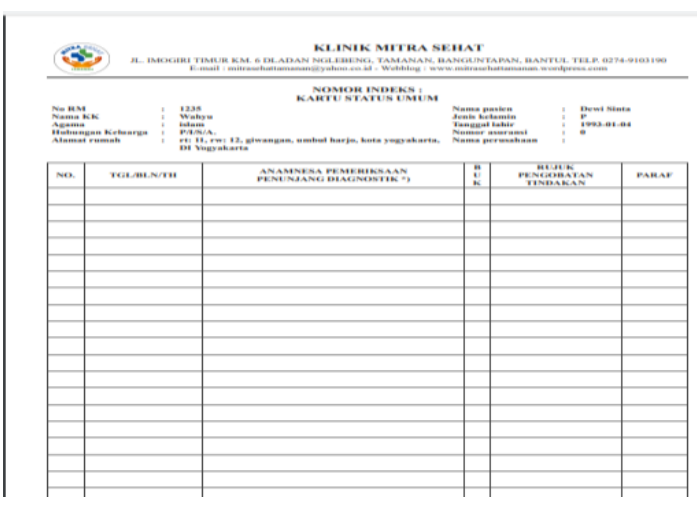

Gambar 10. Formulir rekam medis

Pada menu pelayanan terdapat sub menu pemeriksaan dan cek pemeriksaan.

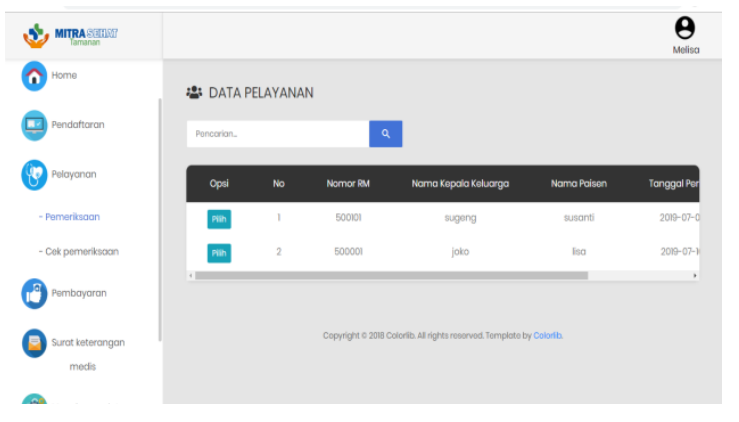

Gambar 11. Sub menu pemeriksaan 


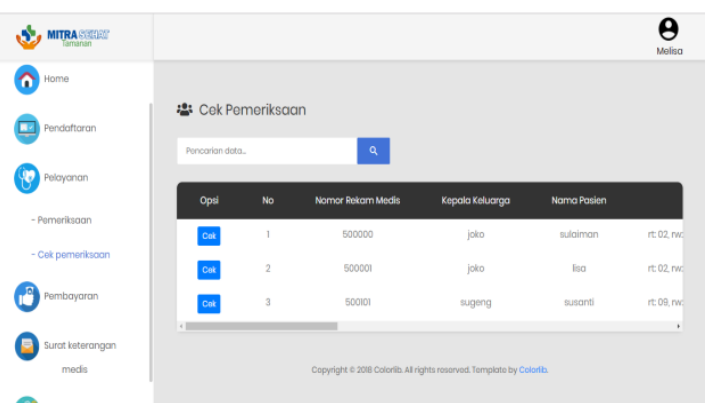

Gambar 12. Sub cek pemeriksaan

Pada menu cek pelayanan tersebut sistem informasi dapat mencetak formulir rekam medis yang berisikan data pelayanan yang telah diterima pasien seperti anamnesa, diagnosa dan tindakan.

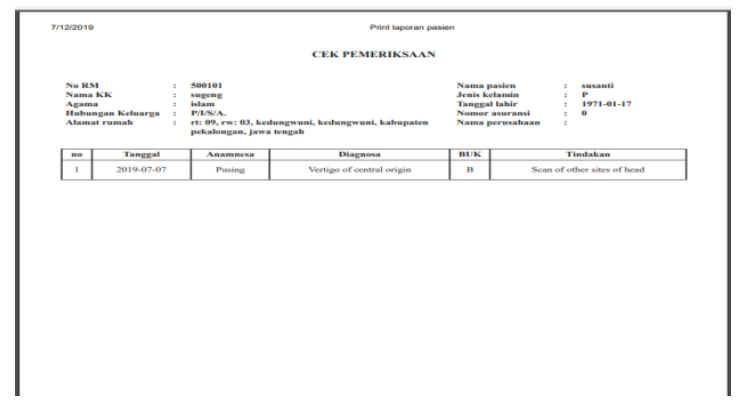

Gambar 13. Lembar rekam medis pasien

Pada halaman ini menampilkan form pembayaran, dimana terdapat opsi bayar untuk melakukan input biaya obat, biaya dokter dan biaya tindakan.

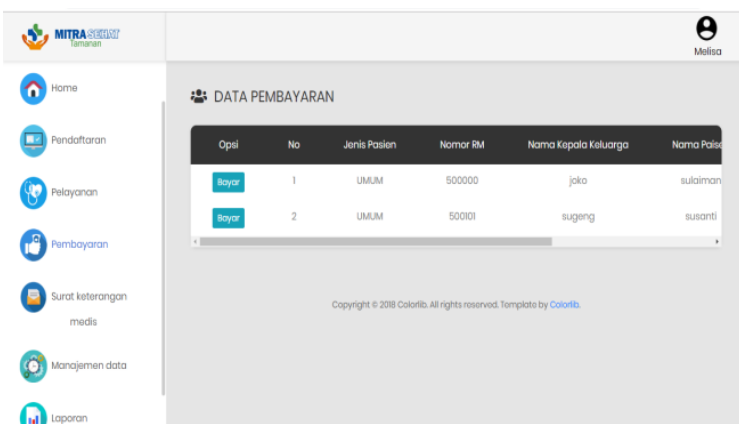

Gambar 14. Menu pembayaran

Pada halaman ini, untuk membuat surat keterangan medis (SKM) baik sehat maupun sakit dapat mencari data pasien di kolom pencarian dengan menggunakan nama ataupun nomor rekam medis.

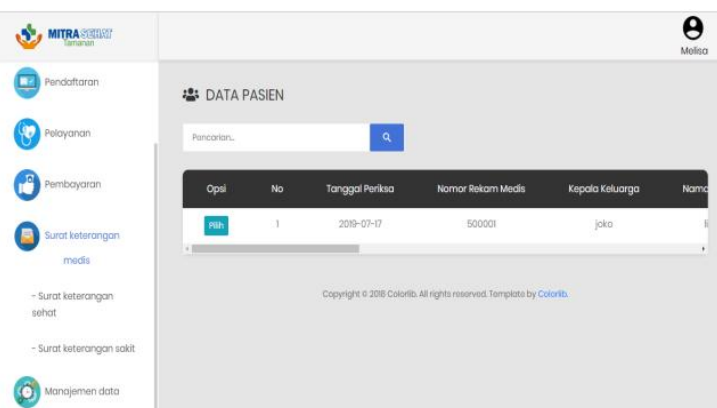

Gambar 15. Menu surat keterangan medis (SKM)

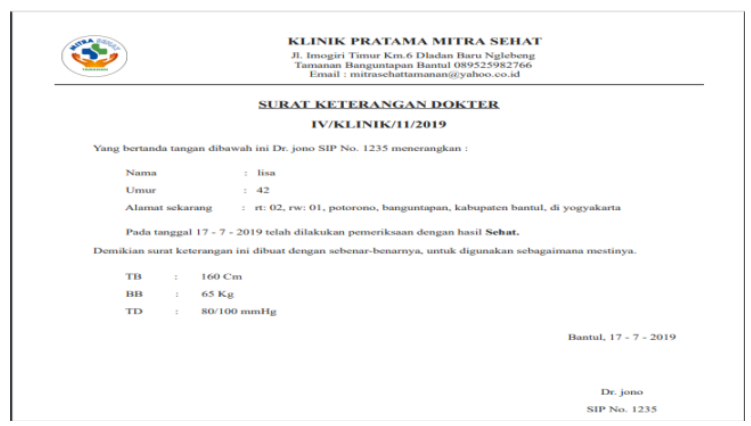

Gambar 16. Surat keterangan medis (SKM)

Pada menu manajemen data terdapat sub menu untuk menambah data user, dokter, obat, jenis pasien, jenis pelayanan, data diagnosa, data tindakan dan data spesialis dokter.

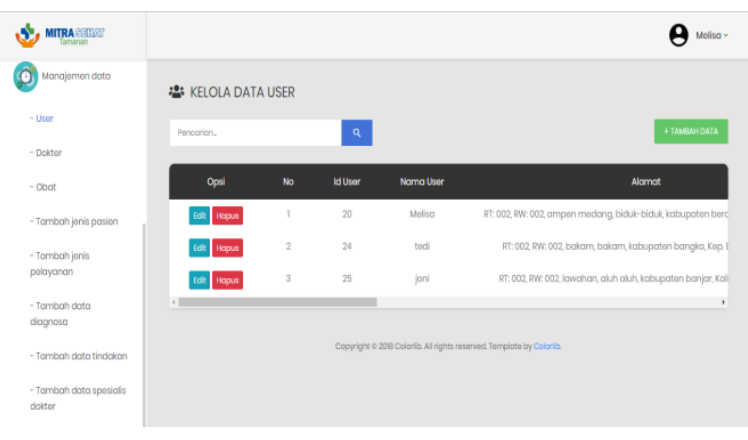

Gambar 17. Sub menu user

Pada menu laporan dapat menampilkan laporan kunjungan pasien, laporan obat dan laporan pembayaran dimana setiap laporan dapat dicetak dan export ke microsoft excel. 


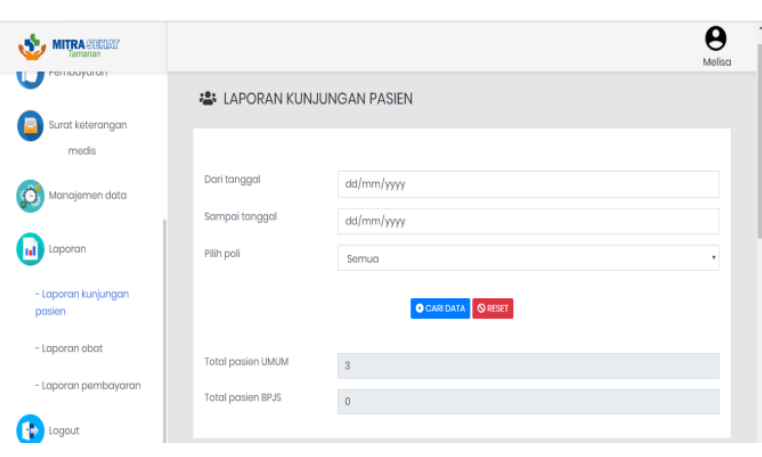

Gambar 18. Sub menu laporan kunjungan pasien

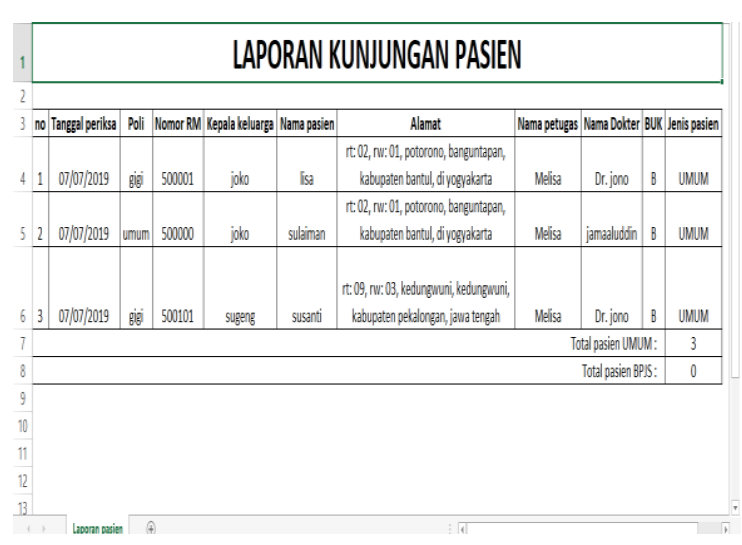

Gambar 19. Export microsoft excel laporan kunjungan pasien

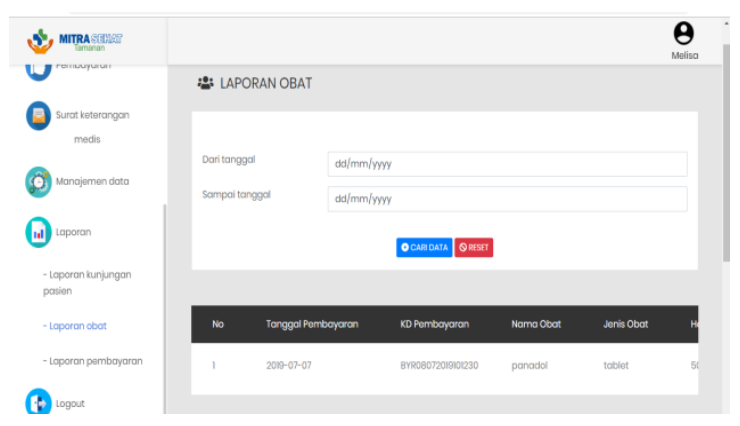

Gambar 20. Sub menu laporan obat

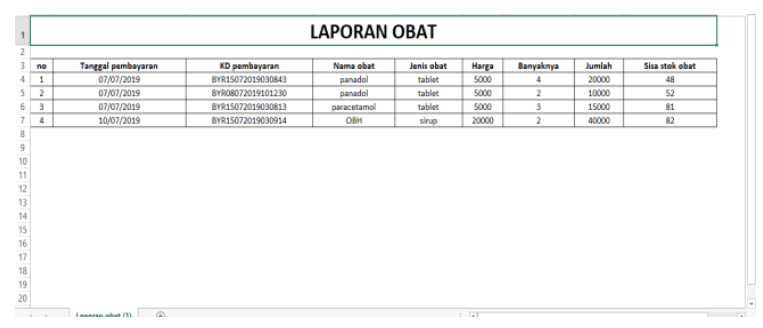

Gambar 21. Export excel laporan obat

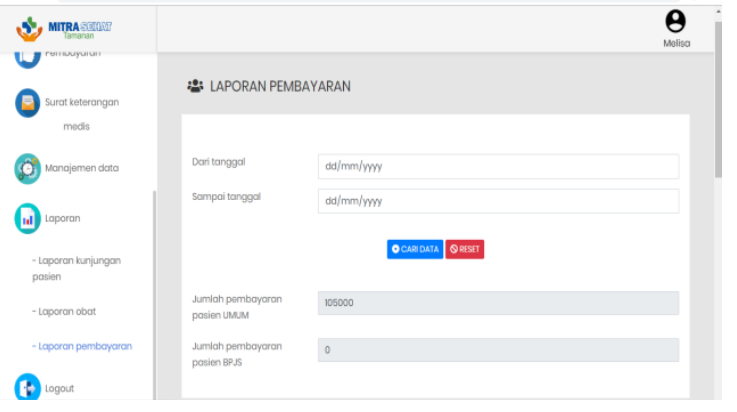

Gambar 22. Sub menu pembayaran

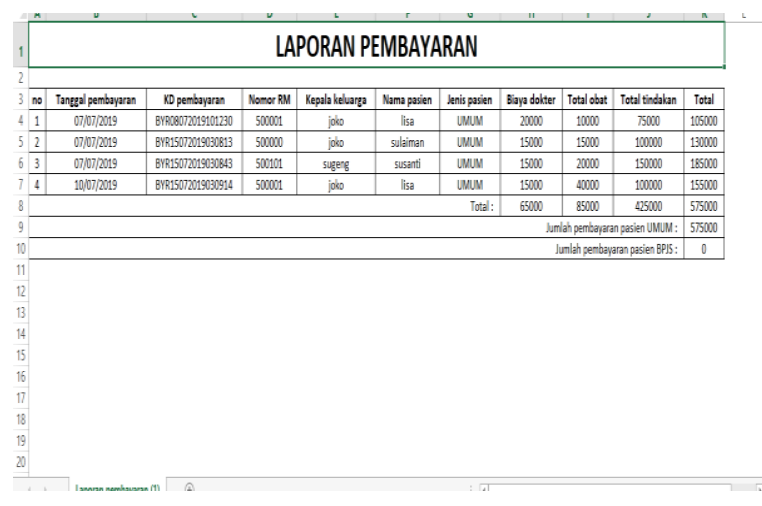

Gambar 23. Export ke excel laporan pembayaran

Sistem informasi yang dirancang penelitian ini adalah sistem informasi manajemen dimana sistem dimulai dari pendaftaran pasien baru, pasien lama, pelayanan pemeriksaan, pembayaran, manajemen data (user, dokter, obat, jenis pasien, jenis pelayanan, data diagnosa, data tindakan, data spesialis dokter) dan laporan (laporan kunjungan pasien, laporan obat, laporan pembayaran). Tahapan sistem yang dilakukan secara berturut-turut dimulai dari perencanaan, analisis, desain, dan implementasi.

Kebutuhan sistem elektronik medical record berbasis web yaitu membuat catatan medis yang dapat diakses oleh staf medis rumah sakit dan pasien untuk membuat sistem perawatan kesehatan lebih efisien. Sistem akan meminimalkan kesalahan karena entri manual data medis pasien dengan akuisisi data informasi medis otomatis. Sistem saat ini lebih cocok untuk rumah sakit menengah dan kecil. Standar ditetapkan untuk mengelola, menyimpan, dan berbagi catatan medis antara penyedia layanan kesehatan yang berbeda (Nguyen, 2011). Layanan web sangat bergantung $X M L$ yang diakui luas dan standar 
internet lainnya untuk membuat infrastruktur yang mendukung interoperabilitas aplikasi. Layanan web dapat digunakan secara internal dalam suatu aplikasi atau terbuka secara eksternal melalui internet untuk digunakan oleh banyak aplikasi. Karena layanan web dapat diakses melalui antarmuka tampilan standar, layanan web memungkinkan sistem yang berbeda untuk bekerja bersama sebagai satu web (Asari, 2013).

Halaman login hanya dapat dibuka oleh admin yang memiliki kode yang telah telah terdaftar dalam sistem informasi (Wijaya, 2017). Pada sistem microsoft excel di Klinik Pratama Mitra Sehat merupakan sistem yang masih sederhana dan belum terdapat keamanannya. Sistem informasi pendaftaran pasien memaksimalkan keamanan dari orangorang yang tidak berhak mengakes karena dilengkapi dengan menu login dimana petugas harus memasukan user dan password yang hanya dapat diakses oleh admin dan user (Rohman, 2019).

Desain interface atau desain antarmuka adalah desain tampilan untuk sistem informasi. tujuan dari penggunaan desain interface adalah untuk membuat interaksi pengguna menjadi sederhana, menarik dan sebaik mungkin (Hakam, 2016). Halaman utama sistem microsoft excel berisi data sosial pasien dimana sistem yang ada pada Klinik Pratama Mitra Sehat tidak ada desain antar muka (interface) sehingga terlihat membosankan. Sehingga perancang mengusulkan untuk dilakukannya perbaikan pada halaman utama yang akan menampilkan informasi klinik tentang kunjungan pasien dan pendapatan serta menggunakan desain interface agar tampilan tidak membosankan.

Halaman pendaftaran pasien yaitu untuk memasukkan data pasien agar data pasien terdaftar di dalam sistem informasi. Pengisian data sosial pada sistem microsoft excel dilakukan saat pertama kali pasien berkunjung di Klinik Pratama Mitra Sehat. Berdasarkan Kata Hat-I yang merupakan Kamus Data Kesehatan Indonesia versi 1.0 terdapat beberapa set data salah satunya set data orang sebagai pasien yang dijadikan sebagai informasi data pasien dimana terdapat struktur elemen dari set data orang sebagai pasien yang dapat dijadikan perbaikan. Perbaikan perancangan pada pendaftaran pasien baru dan tambah data untuk pasien yang salah satu keluarganya sudah pernah berkunjung (family folder) meliputi jenis pasien, nomor asuransi (jika BPJS), nomor rekam medis, nama kepala keluarga, nama pasien, hubungan keluarga, alamat, jenis kelamin, tanggal lahir, umur, agama, pendidikan, status, pekerjaan dan nomor handphone.

Rancangan halaman pemeriksaan adalah untuk menambah data keluhan dan riwayat penyakit, data diagnosa, data tindakan, rencana selanjunya dan tipe konsultasi. Menurut (Permenkes RI No. 269/MenKes/Per/III (2008), rekam medis adalah berkas yang berisikan catatan dan dokumen tentang identitas pasien, pemeriksaan, pengobatan, tindakan dan pelayanan lain yang telah diberikan kepada pasien. Dalam peraturan ini dijelaskan bahwa rekam medis rawat jalan pada sarana pelayanan kesehatan salah satunya memuat hasil pemeriksaan pasien. Pada sistem microsoft excel yang digunakan di Klinik Pratama Mitra Sehat merupakan sistem informasi yang menyimpan data sosial pasien dimana sistem tersebut belum memilik fitur pelayanan (pemeriksaan) dan hanya dapat menampilkan data pasien. Sebelumnya hasil pemeriksaan ditulis manual dalam lembar rekam medis yang memuat anamnesa, pemeriksaan penunjang, diagnosa dan tindakan. Hal ini sangat disayangkan karena dengan berkembangnya teknologi informasi diperlukan suatu sistem yang dapat mengelola pelayanan medis berbasis data maka kegiatan pendaftaran perlu adanya input data pemeriksaan dimana dapat dipenuhi dengan tersedianya sistem pengolah data yang berbasis komputer. Oleh karena itu, perancang membantu untuk menyediakan fitur pelayanan yaitu pemeriksaan yang diharapkan kedepannya dapat membantu mengembangkan rekam medis Klinik Pratama Mitra Sehat.

Menurut Permenkes RI No. 27, (2014) pembiayaan kesehatan merupakan bagian yang penting, salah satu metode pembayaran rumah sakit yang digunakan adalah metode pembayaran retrospektif yang merupakan metode pembayaran yang dilakukan atas layanan kesehatan yang diberikan kepada pasien berdasar pada setiap aktifitas layanan yang diberikan, semakin banyak layanan kesehatan yang diberikan semakin besar biaya yang harus dibayarkan. Pada Klinik Pratama Mitra Sehat sistem yang digunakan untuk pembayaran dilakukan secara manual dengan pencatatan menggunakan buku sehingga 
memungkinkan terjadinya kesalahan. Oleh karena itu, perancang membantu menyediakan fitur pembayaran untuk pasien umum agar dapat menghasilkan informasi dan laporan pembayaran serta meningkatkan mutu Klinik Pratama Mitra Sehat.

Menurut Peraturan Menteri Pendayagunaan Aparatur Negara dan Reformasi Birokrasi RI No. 30, (2013) salah satu jabatan fungsional perekam medis yaitu sebagai pelaksana pemrosesan permintaan surat keterangan medis. Pemrosesan permintaan surat keterangan medis ini yang diberikan dokter dengan keterangan dan pendapat yang telah diperiksa kebenarannya. Jenis surat keterangan dokter yaitu surat keterangan lahir, surat keterangan meninggal, surat keterangan sehat, surat keterangan sakit, surat keterangan cacat, surat keterangan pelayanan medis untuk penggantian biaya dari asuransi kesehatan, surat keterangan cuti hamil, surat keterangan ibu hamil (berpergian dengan pesawat udara), visum et repertum, laporan penyakit menular dan kuitansi. Pembuatan surat keterangan medis pada Klinik Pratama Mitra Sehat terdapat 2 jenis, yaitu surat keterangan sehat dan surat keterangan sakit. Pada sistem microsoft excel belum terdapat fitur cetak surat keterangan sehat dan sakit. Sebelumnya surat keterangan medis dibuat secara manual. Melihat hal tersebut perancang mengusulkan fitur surat keterangan medis (SKM) sehingga akan menghasilkan surat keterangan sehat dan surat keterangan sakit yang diharapkan dapat membantu mengembangkan rekam medis di Klinik Pratama Mitra Sehat.

Manajemen sistem basis data (database management system-DBMS) adalah perangkat lunak yang didesain untuk membantu dalam hal pemeliharaan dan utilitas kumpulan data dalam jumlah besar. DBMS dapat menjadi alternatif penggunaan secara khusus untuk aplikasi, semisal penyimpanan data dalam file (Kristanto, 2018). Manajemen data pada sistem informasi manajemen rawat jalan digunakan untuk penyimpanan dan penambahan data seperti user, dokter, obat, jenis pasien, jenis pelayanan, data diagnosa, data tindakan dan data spesialis dokter dimana hanya petugas penanggung jawab pendaftaran yaitu admin yang dapat mengelola semua menu tersebut. Sehingga perancang mengusulkan adanya fitur ini agar memudahkan petugas jika terdapat penambahan data.
Perancangan sistem informasi pelaporan dimulai dari identifikasi kebutuhan pengguna, perancangan aplikasi dan menguji coba prototype sistem informasi pelaporan posyandu lansia. Pengguna menyatakan menerima prototype, kelengkapan pengisian pelaporan menjadi lebih lengkap, hak akses dapat diatur, dan penghitungan umur sudah otomatis (Rohman, 2018).

Dalam (Permenkes RI No. 1171/MenKes/Per/VI (2011), dijelasken bahwa setiap rumah sakit wajib melakukan pencatatan dan pelaporan tentang kegiatan penyelenggaraan rumah sakit dalam bentuk sistem informasi manajemen. Pada sistem microsoft excel Klinik Pratama Mitra Sehat belum terdapat fitur laporan. Sehingga pembuatan laporan masih dilakukan secara manual yang memungkinkan terjadinya kesulitan bagi petugas dalam pembuatan laporan. Oleh karena itu, perancang membantu untuj menyediakan fitur laporan untuk memudahkan petugas dan membantu meningkatkan mutu Klinik Pratama Mitra Sehat. Sistem informasi pelaporan rekam medis rawat jalan mempermudah petugas dalam mencari data pasien dengan menggunakan fungsi queries, mampu mengolah data pasien serta membuat laporan rekapitulasi kunjungan pasien rawat jalan (Rohman, 2017).

\section{KESIMPULAN}

Sistem microsoft excel hanya menyimpan data sosial, tidak ada keamanan sistem, input data kurang efektif, kontrol sulit dilakukan, pengolahan data dan pembuatan laporan dilakukan secara manual sehingga membutuhkan perbaikan sistem informasi. Perancangan sistem informasi manajemen rawat jalan berbasis web pada Klinik Pratama Mitra Sehat membutuhkan data berupa jenis pasien, nomor asuransi (jika BPJS), nomor rekam medis, nama kepala keluarga, nama pasien, alamat, tanggal lahir, umur, agama, pendidikan, status, pekerjaan dan nomor handphone. Perancangan sistem informasi manajemen rawat jalan berbasis web dapat membantu petugas dalam memberikan pelayanan pendaftaran pasien baru, pendaftaran pasien lama, penyimpanan hasil pemeriksaan, penyimpanan pembayaran, khususnya dalam pembuatan surat keterangan medis dan pembuatan laporan kunjungan pasien, obat dan pembayaran.

\section{DAFTAR PUSTAKA}


Asari Ahmad; Bambang Eka Purnama, (2013), Distributed Data Patient In Medical Record Information System, International Journal of Scientific \& Technology Research (IJSTR) Volume 2, Issue 8, August 2013.

Hakam, F. 2016. Analisis, Perancangan dan Evaluasi Sistem Informasi Kesehatan. Yogyakarta: Gosyen Publishing.

Kristanto, A. 2018. Perancangan Sistem Informasi dan Aplikasinya. Revisi. Yogyakarta: Penerbit Gava Media.

Meianti, Anggia; Rohman, Hendra; Mayretta, Anna. 2018. Perencanaan Implementasi Unit Kerja Rekam Medis Untuk Klinik Pratama Pancasila Baturetno Wonogiri. Jurnal Manajemen Informasi Kesehatan Indonesia (JMIKI), [S.1.], v. 6, n. 2, p. 135-141, des. 2018. ISSN 2337-6007. <http://jmiki.aptirmik.or.id/index.php/jmi ki/article/view/198>. doi:http://dx.doi.org/10.33560/.v6i2.198.

Nguyen, Thuan D., Hai D. VU, John G. Webster, Amit J. Nimunkar, 2011, A Web-Based Electronic Medical Records and Hospital Information System for Developing Countries, Journal of Health Informatics in Developing Countries, https://www.researchgate.net/publication/ 239524799.

Peraturan Menteri Pendayagunaan Aparatur Negara dan Reformasi Birokrasi RI No. 30 2013. Peraturan Menteri Pendayagunaan Aparatur Negara dan Reformasi Birokrasi RI No. 30 Tahun 2013 Tentang Jabatan Fungsional Perekam Medis dan Angka Kreditnya.

Permenkes RI No. 1171/MenKes/Per/VI 2011 Peraturan Menteri Kesehatan Republik Indonesia

No. 1171/MenKes/Per/VI/2011 Tentang Sistem Informasi Rumah Sakit.

Permenkes RI No. 269/MenKes/Per/III 2008. Peraturan Menteri Kesehatan Republik Indonesia. No.269/MenKes/Per/III/2008 tentang Rekam Medis'.

Permenkes RI No. 27 2014. Peraturan Menteri Kesehatan Republik Indonesia Nomor 27 Tahun 2014 Tentang Petunjuk Teknis Sistem Indonesian Case Base Groups (INA-CBGs)'.

Profil Kesehatan Provinsi DI Yogyakarta. 2017. Profil Kesehatan Provinsi DI Yogyakarta Tahun 2017.
Rohman, H; Dewi, CWP; Nuswantoro, MR. 2019. Perancangan Sistem Informasi Pendaftaran Rawat Jalan Berbasis Web Di Klinik Pratama Patalan. Prosiding Nasional Seminar Manajemen Informasi Kesehatan Nasional "Rekam Medis, Informasi Kesehatan, Dan Informatika Kesehatan". $\quad$ pp. 23-31. https://ojs.udb.ac.id/index.php/smiknas/ar ticle/view/689/676.

Rohman, H; Prabawati, BC; Anaskhan, AS. 2019. Pembangunan Sistem Informasi Pendaftaran Rawat Jalan Klinik Pratama Harapan Sehat Berbasis Web. Prosiding Nasional Seminar Manajemen Informasi Kesehatan Nasional "Rekam Medis, Informasi Kesehatan, Dan Informatika Kesehatan". pp. 12-22. https://ojs.udb.ac.id/index.php/smiknas/ar ticle/view/679/671.

Rohman, Hendra. Try Nur Aminaa. 2018. Perancangan Sistem Informasi Pelaporan Posyandu Lansia. Jurnal Manajemen Informasi Dan Administrasi Kesehatan, 1(02). http://jmiakrekammedis-

univetbantara.ac.id/index.php/jmiak/articl e/view/12.

Wijaya, H. 2017. Penerapan Metode Waterfall Pada Sistem Informasi Pendaftaran Pasien Rawat Jalan Berbasis Web Mobile. Jurnal SISFOKOM, 06(September). pp. 80-85. 